\title{
Prevalence of maternal smoking and environmental tobacco smoke exposure during pregnancy and impact on birth weight: retrospective study using Millennium Cohort
} Corinne Ward ${ }^{* 1}$, Sarah Lewis ${ }^{1}$ and Tim Coleman ${ }^{2}$ \author{
Nottingham, Nottingham, UK \\ Email: Corinne Ward* - research@corinneward.co.uk; Sarah Lewis - Sarah.lewis@nottingham.ac.uk; \\ Tim Coleman - Tim.coleman@nottingham.ac.uk \\ * Corresponding author
}

Address: ${ }^{1}$ Division of Epidemiology and Public Health, University of Nottingham, Nottingham, UK and ${ }^{2}$ Division of Primary Care, University of

Published: 16 May 2007

BMC Public Health 2007, 7:8I doi:10.1 I86/I47I-2458-7-8I

This article is available from: http://www.biomedcentral.com/I47/-2458/7/8 I

(C) 2007 Ward et al; licensee BioMed Central Ltd.

This is an Open Access article distributed under the terms of the Creative Commons Attribution License (http://creativecommons.org/licenses/by/2.0), which permits unrestricted use, distribution, and reproduction in any medium, provided the original work is properly cited.
Received: 17 November 2006

Accepted: 16 May 2007

\begin{abstract}
Background: Meta-analyses of studies investigating the impact of maternal environmental tobacco smoke (ETS) on birth weight have not produced robust findings. Although, ante natal ETS exposure probably reduces infant's birth weights, the scale of this exposure remains unknown. We conducted a large, cohort study to assess the impact of ETS exposure on birth weight whilst adjusting for the many factors known to influence this.

Method: Retrospective study using interview data from parents of 18,297 children born in 2000/ 2001 and living in the UK 9 months afterwards (the Millennium Cohort Survey). Comparison of birth weight, sex and gestational age specific (SGA) z score, birth before 37 weeks and birth weight $<2.5 \mathrm{Kg}$ (LBW) in infants born to women exposed to: i) no tobacco smoke, ii) ETS only and iii) maternal smoking whilst pregnant.

Results: 13\% of UK infants were exposed to ETS and $36 \%$ to maternal smoking ante natally. Compared to no ante natal tobacco smoke exposure, domestic ETS lowered infants' adjusted mean birth weights by $36 \mathrm{~g}(95 \% \mathrm{Cl}, 5 \mathrm{~g}$ to $67 \mathrm{~g})$ and this effect showed a dose-response relationship. ETS exposure also caused non-significant increases in the adjusted risks of Low Birth Weight $(<2.5 \mathrm{Kg})$ [OR I.23 (95\% Cl, 0.96 to I.58) and premature birth [OR I.2I (95\% Cl, 0.96 to I.5I)], whilst the impacts of maternal smoking were greater and statistically significant.
\end{abstract}

Conclusion: UK prevalences of domestic ETS exposure and maternal smoking in pregnancy remain high and ETS exposure lowers infants' birth weights.

\section{Background}

Environmental tobacco smoke (ETS) exposure has a clinically significant, detrimental impact on public health $[1,2]$ and so is an important issue for policy makers and clinicians. Maternal smoking during pregnancy impairs fetal growth [3-6]. and shortens gestation causing prema- ture birth [7] with significant fetal and infant mortality and morbidity. ETS contains lower doses of the same toxins that smokers inhale [1], so maternal ETS exposure during pregnancy should have similar but less severe effects. If ETS exposure has even a small impact on fetal growth in the womb, this could translate into significant morbidity 
by increasing the numbers of high-morbidity, low birth weight (LBW) infants [8].

Studies investigating whether or not maternal ETS exposure during pregnancy affects birth outcomes have reported mixed findings $[9,10]$. A review [9] found significant heterogeneity between studies, but still presented synthesised findings and concluded that maternal ETS exposure during pregnancy reduced infants' adjusted mean birth weights by $-24.0 \mathrm{~g}$ [95\% CI $-39.3 \mathrm{~g}$ to $-8.6 \mathrm{~g}]$ and also increased the risks of babies being either "small for gestational age (SGA) or LBW at term" [9]. However, ETS exposure had no impact on the risk of either SGA or LBW at term alone and the reviewers noted that empirical studies were conducted in widely varied settings and often small and of poor quality, reporting only crude (i.e. nonadjusted) birth outcomes. Additionally, this review [9] searched only two databases for papers published before 1995, excluding those for which no English translation was available and it may not have determined the true impact of ETS on birth weight. Although a recent Surgeon General report concluded that ETS exposure reduces birth weight [11], this finding was based on the same review [9] without further literature searching or meta analyses. Consequently, previously calls for large, well-conducted cohort studies which have sufficient power to assess the impact of ETS exposure on birth outcomes whilst adjusting for the many factors known to influence these [9] remain relevant today[12]. We report the findings of such a study using data from the Millennium Survey, a contemporary UK epidemiological birth cohort, to investigate the UK prevalences of domestic ETS exposure and maternal smoking in pregnancy and the relative impact of these exposures on birth weight.

\section{Methods}

This study utilised data collected by the UK Millennium Cohort Study (MCS), in which the parents of 18,819 children $(18,553$ single births), born over a 12 month period between 2000 and 2001, were interviewed when their children were 9 months old (72\% response rate)[13]. Ethical approval was not needed for the analysis presented in this paper, because this involves secondary analysis of data from the MCS and interviewees gave consent for their anonymised, survey responses to be used for research purposes when they agreed to be interviewed for this [13]. Parents gave information regarding their social environment, socioeconomic status, smoking habits, obstetric history and birth outcomes. For the analysis presented here, we included only participants who provided information on their smoking status.

We obtained data from the UK Data Archive[14] and used STATA v.9[15] for analysis. We extracted self reported data on whether and how heavily mothers' had smoked at the start of pregnancy, and if and when, their habits had changed during this pregnancy. Similar data were also available for women's partners. These data were used to allocate cohort women to the following categories reflecting tobacco smoke exposure during pregnancy: i) no tobacco smoke exposure, ii) maternal active smoking at any point during pregnancy and iii) environmental tobacco smoke (ETS) exposure. ETS exposure was defined as occurring when a woman who did not smoke at all whilst pregnant had a partner who reported smoking during the pregnancy. This definition will underestimate total ETS exposure as, for example, occupational exposures were not assessed. We also derived variables with the following categories to indicate the amount smoked by women and their partners: non-smokers, smoking 1-10, 11-20 and over 20 cigarettes daily. Women without a partner and who did not smoke were defined as having no ETS exposure for analysis.

Birth weight data were obtained during interviews with parents (usually mothers) and $90 \%$ of recalled birth weights were validated from Parent Held Child Health Records (PHCHR) which the majority of the cohort used [16]. Gestational age at birth was derived from women's reported estimated date of delivery and their infants' birth dates (also validated from PHCHR). Finally, we extracted data on the following variables that are associated with birth weight [4] and/or shortened gestation [7] and had the potential to act as confounders: maternal age, body mass index at the start of pregnancy, ethnicity, educational level, income, gestational diabetes, alcohol intake and parity (number of previous live births).

\section{Analysis}

The MCS survey participants were sampled by electoral ward, and using a weighted sampling strategy to ensure that that the sample was representative of all four UK countries and achieved higher than average numbers of respondents from economically-deprived areas and ethnic minorities. The MCS survey is thus a disproportionately stratified and clustered sample, and we used STATA survey to allow for clustering and for the weighted sampling to produce unbiased estimates of effect.

We calculated sex and gestational age specific (SGA) z scores from birth weight and gestation data using British birth weight reference data from 1990 and an algorithm, following a standard procedure $[17,18]$. SGA Z scores (or Standard Deviation Scores, SDS) are a measure of birth weight at a stated gestational age, and measured in standard deviations from the mean. Since this measure of weight is adjusted for gestation at birth, it is also a measure of fetal growth in utero. Birth weights under $2.5 \mathrm{~kg}$ were categorised as low birth weight (LBW) and gestation periods of less than 259 days were considered premature. 
We used multiple linear regression to investigate differences between tobacco exposure groups in continuous outcomes (birth weight and SGA $\mathrm{z}$ scores) and logistic regression for dichotomous ones (LBW and prematurity). We examined the effects of potential confounders including maternal age, ethnic group, household income and maternal education, maternal body mass index at the outset of pregnancy, gestational diabetes, parity and maternal alcohol consumption during pregnancy, adjusting for all those that altered the size of effect of smoke exposure on any of the outcome variables. Missing values on each confounder were included as a category in the multivariate analysis, but we repeated the analysis including only those with complete data on all variables and confirmed that the results were very similar.

\section{Results}

Of the 18,819 children in the Millennium cohort, 30 were triplets and 492 were twins. Consequently, of the 18,553 families within the study, 18,297 involved single births and these are those which contribute data to this analysis. There was complete smoking data at the start of pregnancy for 18,220 (99.6\%) mothers, of whom 35\% were smokers and about two-thirds of these were still continuing to smoke 6 months into their pregnancy. There was com- plete smoking data for 12,751 (85.5\%) of their 14,859 partners, of whom $39 \%$ were smoking at the start of pregnancy, and most (94\%) continued to smoke at 6 months of pregnancy. We were able to derive tobacco smoke exposure at the start of pregnancy for $16,756(91.6 \%)$ of the mother-singleton infant pairs. Of these, $8100(48.3 \%)$ mothers were not exposed to any tobacco smoke, 6397 (38.2\%) were active smokers and 2259 (13.5\%) were ETS exposed. After allowing for the sampling weights to attain figures representative of the UK population, the prevalence of exposure to maternal smoking and to ETS exposure at the start of pregnancy, were $36 \%$ and $13 \%$ respectively.

Table 1 shows the characteristics of women and babies included in the analysis, and those who were excluded due to missing smoking data. Those who were excluded were primarily non-smoking mothers with partners who did not provide smoking information and were more likely to be Asian, but otherwise similar in characteristics to the remaining non-smoking mothers. The distributions of maternal age, BMI, parity, household income, ethnicity, and maternal education differed between tobacco smoke exposure groups, and were treated as potential confounders in the analysis. Gestational diabetes was

Table I: Maternal characteristics by smoking status (unadjusted for sample weighting)

\begin{tabular}{|c|c|c|c|c|}
\hline $\begin{array}{l}\text { Maternal } \\
\text { Characteristics }\end{array}$ & $\begin{array}{l}\text { Non-smoker, non ETS } \\
\text { exposed }(n=8100)\end{array}$ & $\begin{array}{l}\text { Non-smoker, ETS } \\
\text { exposed }(n=2259)\end{array}$ & Active smoker $(n=6397)$ & $\begin{array}{l}\text { Excluded due to missing } \\
\text { smoking data }(n=154 I)\end{array}$ \\
\hline $\begin{array}{l}\text { Maternal age at birth } \\
\text { Mean (SD) }\end{array}$ & $29.6(5.6)$ & $28.7(5.5)$ & $26.2(6.0)$ & $29.2(5.8)$ \\
\hline BMI Mean (SD) & $24.0(4.4)$ & $24.0(4.8)$ & $23.2(4.4)$ & $23.8(4.4)$ \\
\hline \multicolumn{5}{|l|}{$\begin{array}{l}\text { Parity (previous live } \\
\text { births) } N(\%) *\end{array}$} \\
\hline None & $3310(42.2)$ & $862(40.1)$ & $2838(45.2)$ & $496(36.0)$ \\
\hline $1-2$ & $3952(50.4)$ & $1083(50.4)$ & $2882(45.9)$ & $750(54.5)$ \\
\hline 3 or more & $572(7.3)$ & $203(9.4)$ & $553(8.8)$ & $13 \mid(9.5)$ \\
\hline $\begin{array}{l}\text { Alcohol use in } \\
\text { pregnancy } N(\%)\end{array}$ & $622(7.7)$ & $157(7.0)$ & $684(10.7)$ & $98(6.6)$ \\
\hline \multicolumn{5}{|l|}{ Ethnicity N (column \%) * } \\
\hline White & $650 \mathrm{I}(80.4)$ & I70| (75.4) & $6058(94.9)$ & $1018(68.2)$ \\
\hline Asian & $872(10.8)$ & $412(18.3)$ & $76(1.2)$ & $364(24.4)$ \\
\hline Black & $438(5.4)$ & 43 (1.9) & $117(1.8)$ & $64(4.3)$ \\
\hline Mixed or other & $275(3.4)$ & $100(4.4)$ & $134(2.1)$ & $46(3.1)$ \\
\hline \multicolumn{5}{|l|}{$\begin{array}{l}\text { Education N (column \%) } \\
*\end{array}$} \\
\hline Degree & $1942(24.0)$ & $320(14.2)$ & $351(5.5)$ & $247(16.4)$ \\
\hline Diploma or A level & $1714(21.2)$ & $440(19.5)$ & $789(12.4)$ & $278(18.5)$ \\
\hline O levels & $3090(38.2)$ & $938(4 \mid .6)$ & $340 I(53.3)$ & $633(42.1)$ \\
\hline None of the above & $1342(16.6)$ & $558(24.7)$ & $1840(28.8)$ & $347(23.1)$ \\
\hline \multicolumn{5}{|l|}{$\begin{array}{l}\text { Income }(£) \mathbf{N}(\text { column \%) } \\
*\end{array}$} \\
\hline Less than 10,400 & $1482(19.9)$ & $424(20.3)$ & $2514(42.2)$ & $256(20.9)$ \\
\hline 10,400 to 20,800 & $2194(29.5)$ & $835(40.0)$ & $2058(34.5)$ & $453(37.0)$ \\
\hline 20,800 to 31,300 & $1723(23.2)$ & $469(22.5)$ & $822(13.8)$ & $240(19.6)$ \\
\hline Above 31,200 & $2035(27.4)$ & $358(17.2)$ & $568(9.5)$ & $277(22.6)$ \\
\hline
\end{tabular}

* where numbers in column do not add up to column total, this is due to missing data 
uncommon at $2 \%$ in non-exposed, $2.5 \%$ in ETS exposed, and $1.4 \%$ in active smokers.

After allowing for the sampling weights, the crude mean birth weights in non-exposed, ETS-only exposed and maternal smoking groups were $3.448,3.389$ and $3.279 \mathrm{Kg}$ respectively (Table 2). Crude mean birth weight was lower in infants born to women in both tobacco smoke exposure groups than in non-exposed [for ETS exposed, mean difference $=-59 \mathrm{~g}(95 \% \mathrm{CI}-0.090$ to -0.027$)$ and for maternal smoking $=-168 \mathrm{~g}(95 \% \mathrm{CI}-0.191$ to -0.146$)]$. Adjustment for maternal age, BMI, parity, alcohol use in pregnancy, household income, maternal education, maternal or the child's ethnic group and gestational diabetes, reduced the sizes of these effects to $-36 \mathrm{~g}$ and $-146 \mathrm{~g}$ respectively, but birth weight in both tobacco exposure groups remained significantly lower than in non-exposed. Table 2 shows a similar pattern of results for SGA $\mathrm{z}$ scores, though the reduction in the ETS exposed group compared to the non-exposed was not significant after adjustment for potential confounders.

Table 3 compares the incidence of low birth weight (LBW) and premature babies in the different groups. Maternal smoking significantly increased the risk of LBW (adjusted $\mathrm{OR}=1.92(1.60-2.29), \mathrm{p}<0.001)$ and ETS exposure was associated with a smaller and non-significant rise in LBW incidence (adjusted $\mathrm{OR}=1.23(0.96,1.58), \mathrm{p}=0.1)$. Prematurity increased significantly with maternal smoking (adjusted OR $=1.25(1.05-1.48), p=0.013)$ but the smaller increase in the ETS-exposed group was not significant after adjusting for potential confounders $(\mathrm{OR}=1.21$ (0.96-1.51), $\mathrm{p}=0.11$ ).

Table 4 shows how birth weight varies with the reported amount smoked by maternal smokers and with different levels of ETS exposure (i.e. number of cigarettes per day smoked by partners of non-smokers). In the adjusted model, there was a significant linear trend for reduced birth weight with increasing level of exposure for both maternal smoking and ETS exposures.

\section{Discussion}

We found that tobacco smoke exposure in utero, remains a public health challenge for the UK as $13 \%$ of UK infants born between 2000 and 2001 were exposed to ETS and $36 \%$ to maternal smoking. Compared to no tobacco smoke exposure during pregnancy, domestic ETS exposure and maternal smoking significantly lowered infants' adjusted mean birth weights by $36 \mathrm{~g}$ (95\% CI, $5 \mathrm{~g}$ to $67 \mathrm{~g}$ ) and $146 \mathrm{~g}(122 \mathrm{~g}$ to $171 \mathrm{~g})$ respectively and there was an exposure-response relationship between both reported exposures and adjusted mean birth weights. Maternal smoking caused significant reductions in adjusted SGA z scores, and the adjusted risks of LBW and premature births and ETS exposure also produced adverse changes in these outcomes, which were non-significant after adjustment for potential confounding.

This large cohort study has enough power to assess the impact of ETS exposure on birth outcomes whilst adjusting for the principal factors which affect these. Whilst some earlier studies were of a similar size, these reported only unadjusted changes in birth outcomes, and consequently may have over-estimated the impact of ETS $[19,20]$. Another strength of this study is that the validity of birth outcome data from the MCS is likely to be high. Data were collected by trained interviewers using a standardised interview schedule who were able to refer to parent held child health records in the vast majority of cases [16] and these records included birth weight and gestational age at birth.

A weakness of the study is the potential for recall bias in the retrospectively-obtained, self-reported data on tobacco smoke exposures. However, during pregnancy

Table 2: Associations between birth weight, SGA z score, and tobacco smoke exposure

\begin{tabular}{|c|c|c|c|}
\hline & Non-smoker, non ETS exposed & Non-smoker ETS exposed & Active smoker \\
\hline Birth weight (in Kg) & $N=8091$ & $N=2256$ & $N=6395$ \\
\hline Mean Birthweight (SE) $\dagger$ & $3.448(0.007)$ & $3.389(0.014)$ & $3.279(0.009)$ \\
\hline $\begin{array}{l}\text { Crude mean difference compared to Non- } \\
\text { Smoker, Non ETS exposed }(95 \% \mathrm{Cl})\end{array}$ & - & $\begin{array}{c}-0.059(-0.090 \text { to }-0.027) \\
p<0.001\end{array}$ & $\begin{array}{c}-0.168(-0.191 \text { to }-0.146) \\
P<0.001\end{array}$ \\
\hline Adjusted Mean difference* $(95 \% \mathrm{Cl})$ & - & $\begin{array}{c}-0.036(-0.067 \text { to }-0.005) \\
P=0.025\end{array}$ & $\begin{array}{c}-0.146(-0.171 \text { to }-0.122) \\
p<0.001\end{array}$ \\
\hline SGA z score & $N=8024$ & $N=2228$ & $N=6338$ \\
\hline Mean Z score (SD) $\dagger$ & $0.077(0.014)$ & $0.006(0.026)$ & $-0.237(0.016)$ \\
\hline $\begin{array}{l}\text { Crude mean difference compared to Non- } \\
\text { Smoker, Non ETS exposed }(95 \% \mathrm{Cl})\end{array}$ & - & $\begin{array}{c}-0.070(-0.128 \text { to }-0.013) \\
P=0.016\end{array}$ & $\begin{array}{c}-0.314(-0.354 \text { to }-0.273) \\
P<0.001\end{array}$ \\
\hline Adjusted Mean difference* $(95 \% \mathrm{Cl})$ & & $\begin{array}{c}-0.038(-0.093 \text { to } 0.018) \\
p=0.18\end{array}$ & $\begin{array}{c}-0.275(-0.319 \text { to }-0.231) \\
P<0.001\end{array}$ \\
\hline
\end{tabular}

* Adjustment was made for maternal age, BMI, parity, alcohol use, maternal education, ethnicity, income, gestational diabetes.

$\dagger$ All results are adjusted for the sampling design 
Table 3: Associations between low birth weight, prematurity, and tobacco exposure

\begin{tabular}{|c|c|c|c|}
\hline & Non-smoker, non ETS exposed & Non-smoker ETS exposed & Active smoker \\
\hline Low birth weight & $N=8091$ & $N=2256$ & $N=6395$ \\
\hline Birth weight $<2.5 \mathrm{Kg} \% \dagger$ & 4.4 & 6.0 & 8.3 \\
\hline $\begin{array}{c}\text { Crude Odds Ratio compared to Non-Smoker, Non ETS } \\
\text { exposed }(95 \% \mathrm{Cl})\end{array}$ & 1 & $\begin{array}{l}1.39(1.10,1.77) \\
P=0.007\end{array}$ & $\begin{array}{c}1.97(1.68,2.32) \\
P<0.001\end{array}$ \\
\hline Adjusted Odds Ratio * $(95 \% \mathrm{Cl})$ & 1 & $\begin{array}{l}1.23(0.96,1.58) \\
\quad p=0.10\end{array}$ & $\begin{array}{c}1.92(1.60,2.29) \\
P<0.001\end{array}$ \\
\hline Prematurity & $N=8032$ & $N=2230$ & $N=6339$ \\
\hline Gestation $<37$ weeks $\% \dagger$ & 6.1 & 7.5 & 8.1 \\
\hline $\begin{array}{c}\text { Crude Odds Ratio compared to Non-Smoker, Non ETS } \\
\text { exposed }(95 \% \mathrm{Cl})\end{array}$ & I & $\begin{array}{c}1.26(1.01,1.57) \\
P=0.04\end{array}$ & $\begin{aligned} 1.36 & (1.17,1.58) \\
P & <0.001\end{aligned}$ \\
\hline Adjusted Odds Ratio * $(95 \% \mathrm{Cl})$ & 1 & $\begin{array}{l}1.21(0.96,1.51) \\
\quad p=0.11\end{array}$ & $\begin{array}{c}1.25(1.05,1.48) \\
P=0.013\end{array}$ \\
\hline
\end{tabular}

* Adjustment was made for Maternal Age, BMI, parity, alcohol use, maternal education, income, ethnicity, gestational diabetes

† All results are adjusted for the sampling design

most women are very conscious of the need to restrict exposure of their developing babies to harmful substances like tobacco smoke, so most MCS participants will probably have been able to recall exposures correctly. Some might have deliberately concealed tobacco smoke exposure during pregnancy in order to give a socially desirable response to interviewers. If present, this bias would tend to reduce the observed effects of tobacco smoke on birth outcomes making it harder to detect differences. We did not have data on ETS exposure from other sources (e.g. recreational or occupational) and if any of these exposures were correlated with domestic exposure, then we may have over-estimated the impact of domestic ETS exposure alone. In contrast, around $10 \%$ of Millennium Cohort Survey households were shared by 'non-partner' adults (e.g. grandparents) and we know nothing about such adults smoking behaviour. Consequently, we may have under-estimated the prevalence of domestic exposure to ETS and a small number of infants may have been misclassified as not ETS-exposed when they actually were which would tend to weaken any apparent effect of ETS on birth weight. The fact that we demonstrated an exposure-response relationship between adjusted birth weight and reported domestic ETS exposure, however, provides evidence that this is a true effect and is consistent with studies which have found dose-response relationships between bio-chemical measures of tobacco exposures and birth weight [21-23].

Of infants born within the UK around the millennium, over one third had mothers who smoked, despite the widely publicised adverse impact of smoking on fetal development. In the US, however, only $10.2 \%$ of mothers smoked whilst pregnant in 2004, [24] which illustrates that the threat to public health from maternal smoking in pregnancy can be reduced and emphasises the need for action against this in the UK. For our analyses, we used tobacco smoke exposures which participants recalled

Table 4: Association between level of tobacco smoke exposure during pregnancy and birth weight $(\mathrm{Kg})$

\begin{tabular}{|c|c|c|c|c|}
\hline & Mean birth weight (SE) & $\begin{array}{l}\text { Mean difference from non- } \\
\text { smoker }(95 \% \mathrm{Cl})\end{array}$ & $\begin{array}{l}\text { Adjusted mean difference } \\
\text { from non-smoker }(95 \% \mathrm{Cl})\end{array}$ & $P$ value for trend \\
\hline \multicolumn{5}{|l|}{$\begin{array}{l}\text { ETS exposure (Level of } \\
\text { partner cigarette } \\
\text { consumption in non- } \\
\text { smokers) }\end{array}$} \\
\hline Non-smoker or no partner & $3.448(0.007)$ & - & - & \\
\hline Smoker I-10 cigs/day & $3.386(0.020)$ & $-0.062(-0.103,-0.021)$ & $-0.027(-0.067,0.014)$ & 0.007 \\
\hline Smoker II-20 cigs/day & $3.390(0.024)$ & $-0.058(-0.107,-0.008)$ & $-0.053(-0.101,-0.004)$ & \\
\hline Smoker 20+ cigs/day & $3.407(0.042)$ & $-0.040(-0.124,0.044)$ & $-0.059(-0.141,0.023)$ & \\
\hline \multicolumn{5}{|l|}{$\begin{array}{l}\text { Active Smoker (Level of } \\
\text { Maternal cigarette } \\
\text { consumption) }\end{array}$} \\
\hline Non-smoker & $3.429(0.006)$ & - & - & \\
\hline Smoker I-10 cigs/day & $3.325(0.012)$ & $-0.104(-0.130,-0.078)$ & $-0.086(-0.114,-0.059)$ & $<0.001$ \\
\hline Smoker II-20 cigs/day & $3.239(0.014)$ & $-0.190(-0.220,-0.160)$ & $-0.190(-0.221,-0.159)$ & \\
\hline Smoker $20+$ cigs/day & $3.152(0.032)$ & $-0.277(-0.342,-0.213)$ & $-0.275(-0.34 I,-0.209)$ & \\
\hline
\end{tabular}


from the time that their pregnancies were confirmed (i.e. the start of pregnancy) and also subsequent reports of changes in smoking status, so that active maternal smoking at any point during pregnancy could be determined. Only around $4 \%$ of women's partners changed their smoking status as pregnancies progressed, so the impact of ETS exposure was relatively constant during pregnancy and we observed a similar effect of ETS exposure on birth weight, irrespective of the point in gestation at which this was assessed. Maternal smoking was more likely to change during pregnancy than partner smoking, with $27 \%$ of mothers who smoked at the start of pregnancy reported to have stopped as their pregnancy progressed. Consequently, our findings may under estimate, to some degree, the impact of maternal smoking on birth outcomes, but we chose not to present these findings in detail because the focus of this manuscript is on the overall impact of ETS exposure on birth weight. We found that domestic ETS exposure lowered MCS infants' birth weights by approximately $25 \%$ of the reduction that one would expect from maternal smoking. Trends within the data suggest that domestic ETS exposure may also have caused some preventable morbidity and mortality by increasing the incidence of LBW infants and prematurity, but our sample size was not large enough for these effects to reach statistical significance. However, as the Millenium Cohort Survey contained no information on previous preterm birth, we have not been able to adjust for this important predictor of prematurity in subsequent births, so study findings relating to this outcome must be treated with some caution. Generally, though, higher levels of maternal ETS exposure appear to cause more harm to unborn children, so infants born to women exposed to the very highest ETS levels, such as bar staff, may be particularly at risk.

\section{Conclusion}

Study findings emphasise the continued need for action against maternal tobacco smoke exposure in the UK in order to eliminate fetal harm that still results from this. They also provide further, strong evidence for an end to tobacco smoking in all enclosed areas. Some countries have introduced, or are considering, legislation to prevent smoking in enclosed public spaces [1] and, where introduced, this should have a positive effect on birth outcomes. As ETS exposure from domestic sources has a significant impact on birth weight, any similar legislation introduced into the UK should be accompanied by educational programmes to emphasise the fetal harm that may occur as a consequence of both active and passive maternal smoking within of pregnant women's homes.

\section{Competing interests}

The author(s) declare that they have no competing interests.

\section{Authors' contributions}

All authors participated in the design of the study. SL and TC had the idea for the study and developed a study protocol. CW and SL analysed data and all authors interpreted findings and wrote the paper. SL and TC are guarantors for data contained within the paper. All authors have read and approved the final version of this manuscript.

\section{Acknowledgements}

The authors wish to thank Mrs Rosemary Henson for secretarial assistance. This work was not funded but completed as part of a medical student BMedSci thesis.

\section{References}

I. Tobacco Advisory Group of the Royal College of Physicians: Going smoke-free: The case for clean air in the home, at work and in public places London: Royal College of Physicians of London; 2005.

2. Edwards R, Coleman T, Edwards R, Coleman T: Going smoke-free: the medical case for clean air in the home, at work and in public places. Clinical Medicine 2005, 5:548-550.

3. Robinson JS, Moore VM, Owens JA, McMillen IC: Origins of fetal growth restriction. European Journal of Obstetrics, Gynecology, \& Reproductive Biology 2000, 92: I3-19.

4. Kramer MS: Determinants of low birth weight: methodological assessment and meta-analysis. Bulletin of the World Health Organization 1987, 65:663-737.

5. US Department of Health and Human Services. Women and smoking: a report of the Surgeon General. 2001. Rockille, USDHHS.

6. Tobacco Advisory Group of the Royal College of Physicians: Nicotine addiction in Britain London: Royal College of Physicians of London; 2000.

7. Nabet C, Ancel PY, Burguet A, Kaminski M: Smoking during pregnancy and preterm birth according to obstetric history: French national perinatal surveys. Paediatric and Perinatal Epidemiology 2005, 19:88-96.

8. Arias E, MacDorman MF, Strobino DM, Guyer B: Annual summary of vital statistics - 2002. Pediatrics 2003, I I 2: I 2 I 5- 1230.

9. Windham GC, Eaton A, Hopkins B: Evidence for an association between environmental tobacco smoke exposure and birthweight: a meta-analysis and new data. Paediatric and Perinatal Epidemiology 1999, 13:35-57.

10. Misra DP, Nguyen RH, Misra DP, Nguyen RH: Environmental tobacco smoke and low birth weight: a hazard in the workplace? Environmental Health Perspectives 1999, I07(Suppl 6):897-904.

II. U.S.Dept.of Health and Human Services. The health consequences of involuntary exposure to tobacco smoke : a report of the Surgeon General. 2006. U.S. Dept. of Health and Human Services, Centers for Disease Control and Prevention, Coordinating Center for Health Promotion, National Center for Chronic Disease Prevention and Health Promotion, Office on Smoking and Health.

12. Witorsch RJ, Witorsch P: Environmental tobacco smoke and birthweight of offspring: A critical review and analysis of the epidemiological literature. Indoor and Built Environment 1996, 5:219-23।.

13. Plewis I, Calderwood L, Hawkes D, Hughes G, Joshi H: Millennium cohort study first survey technical report on sampling London, Centre for Longitudinal Studies; 2004.

14. Anonymous. SN4683 Millennium Cohort Study first survey 200 I-2003. UK Data Archive 2005. UK Data Archive. I-I 02005.

15. Anonymous: STATA Texas, USA., Stata Corporationa; 2003.

16. Walton S, Bedford H, Dezateux C, the Millennium Cohort Study Child Health Group: Use of personal child health records in the UK: findings from the millennium cohort study. BMJ 2006, 332:269-270.

17. Gardosi J, Mongelli M, Wilcox M, Chang A: An adjustable fetal weight standard. Ultrasound Obstet Gynecol 1995, 6: I68-I74. 
18. Gardosi J, Francis A: Software programme for the calculation of customised birth weight percentiles. [3.0]. 2003.

19. Underwood PB, Kesler KF, Olane JM, Callagan DA: Parental Smoking Empirically Related to Pregnancy Outcome. Obstetrics and Gynecology 1967, 29:1.

20. Macmahon B, Alpert M, Salber E): Infant Weight and Parental Smoking-Habits. American Journal of Epidemiology 1965, 82:247-261.

21. Eskenazi B, Prehn AW, Christianson RE: Passive and Active Maternal Smoking As Measured by Serum Cotinine - the Effect on Birth-Weight. American Journal of Public Health 1995, 85:395-398.

22. Gomez C, Berlin I, Marquis P, Delcroix M: Expired air carbon monoxide concentration in mothers and their spouses above 5 ppm is associated with decreased fetal growth. Prev Med 2005, 40:10-15.

23. Hanke W, Sobala W, Kalinka J: Environmental tobacco smoke exposure among pregnant women: impact on fetal biometry at 20-24 weeks of gestation and newborn child's birth weight. International Archives of Occupational and Environmental Health 2004, 77:47-52.

24. Martin Joyce A, Hamilton Brady E, Sutton Paul D, Ventura Stephanie J, Menacker Fay, Kirmeyer Sharon: Births: Final Data for 2004. 2006. US Department of Health and Human Services, Center for Disease Control and Prevention, National Centre for Health Statistics, National Vital Statistics System. National Vital Statistics Reports. .

\section{Pre-publication history}

The pre-publication history for this paper can be accessed here:

http://www.biomedcentral.com/1471-2458/7/81/prepub

Publish with Biomed Central and every scientist can read your work free of charge

"BioMed Central will be the most significant development for disseminating the results of biomedical research in our lifetime. "

Sir Paul Nurse, Cancer Research UK

Your research papers will be:

- available free of charge to the entire biomedical community

- peer reviewed and published immediately upon acceptance

- cited in PubMed and archived on PubMed Central

- yours - you keep the copyright

Submit your manuscript here:

http://www.biomedcentral.com/info/publishing_adv.asp 